\title{
Correction to: Using Satellite Data for CBRN (Chemical, Biological, Radiological, and Nuclear) Threat Detection, Monitoring, and Modelling
}

\author{
Gary Sutlieff $^{1}$ (D) $\cdot$ Lucy Berthoud $^{2} \cdot$ Mark Stinchcombe $^{2}$
}

Published online: 11 July 2021

(c) Springer Nature B.V. 2021

\section{Correction to: Surveys in Geophysics (2021) 42:727-755 https://doi.org/10.1007/s10712-021-09637-5}

The original version of this article unfortunately contained a misprint in the article highlights section. On page 727, the first article highlight in the PDF version of the article reads "There lite data in fields that are of interest to CBRN detection and monitoring."

Instead, it should read "There is a wide range of existing satellite data in fields that are of interest to CBRN detection and monitoring." This is not the case for the website version of the article, but the misprint was present in the journal version and PDF version of the article.

Publisher's Note Springer Nature remains neutral with regard to jurisdictional claims in published maps and institutional affiliations.

The original article can be found online at https://doi.org/10.1007/s10712-021-09637-5.

Gary Sutlieff

gary.sutlieff@bristol.ac.uk

1 Department of Aerospace Engineering, University of Bristol, Bristol BS8 1TR, UK

2 Thales Alenia Space UK, Building 660, Business Park, Coldharbour Ln, Stoke Gifford, Bristol BS16 1EJ, UK 